\title{
Morphological characterization with image analysis of cocoa beverage powder agglomerated with steam
}

\author{
Fernanda Zaratini VISSOTTO ${ }^{*}$, Raquel Carolina GIAROLA, Lívia Calegari JORGE ${ }^{1}$, Gisele Tokie MAKITA, \\ Gina Maria Bueno Quirino CARDOZO ${ }^{1}$, Maria Isabel RODRIGUES², Florencia Cecilia MENEGALLI²
}

\begin{abstract}
In this study, the morphological characteristics of cocoa beverage powder granules under minimal, average, and maximal process conditions of a steam agglomerator were studied. A stereoscopic microscope coupled to a digital camera was used for the morphological analysis. The images were analyzed to obtain shape and size descriptors. Aiming to evaluate the descriptors, 150 particles were analyzed. The results showed that there was no difference between the shape descriptors - compacity, circularity, roughness, and aspect ratio - in the operating conditions evaluated. It was observed that the cocoa beverage powder granules are elongated in shape. The size descriptors, area, perimeter, perimeter of convex bounding polygon, minimal and maximal Feret diameter, were different in the process conditions for the granules of size above $600 \mu \mathrm{m}$. As for the minimal process conditions, especially due to low solid feed rates, there is an increase in the size descriptor values. In addition, under the minimum process conditions, in which there is low solid feed rate $(400 \mathrm{~g} / \mathrm{min})$ for a steam pressure of 1.0 bar, it was obtained a good granular condition with retention of $81.1 \%$ of granules on sieves with aperture size between 300 and $1190 \mu \mathrm{m}$.
\end{abstract}

Keywords: agglomeration; steam; cocoa beverage powder; morphological analysis; particle shape; particle size.

\section{Introduction}

\subsection{Cocoa beverage powder and steam agglomeration}

During the production of cocoa beverage powder, the raw materials, cocoa, sucrose, and maltodextrin, were mixed and agglomerated. The focus is to obtain an instant drink with adequate solubility without fine powder, which can cause problems during processing and handling (Iveson et al., 2001; Knight, 2001; Palzer, 2005).

The process of agglomeration can transform a fine powder into granules, with changes in structural and physical properties such as size, porosity, shape, and density. The characteristics of the granules obtained depend on the type of process used, such as steam jet (Hogekamp et al., 1996; Hogekamp, 1999a, b; Hla \& Hogekamp, 1999), fluidized bed (Kowalska \& Lenart, 2005), and thermal agglomeration (Omobuwajo et al., 2000) among other processes; operating conditions; and the ingredients of the formulation and their proportion. Steam jet agglomeration is a process of wet granules growth; and initially the product is a dry powder composed of single particles

Usually in the agglomeration zone of the steam agglomerator, steam jets are directed towards the powder-form material flow in order to moisten the powder, and the contact of the liquid binder with the cold surface of the particle cause condensation. Viscous bridges are then formed between the moistened particles of powder, with consequent granules formation. Subsequent drying of the granules occurs (Hogekamp et al., 1996).
Depending on the operating conditions of the agglomerator, it is possible to obtain granules with different shapes and sizes.

The changes in the physical structure of the powder that occur due to the steam agglomeration process are mostly related to the size and shape of the granules, which makes possible to observe them using morphological analysis.

\subsection{Analysis of particle shape and size}

Imaging devices such as microscopes coupled to computers provide numerical particle images. Based on these bidimensional images, the particle outline can be analyzed for a quantitative assessment of the particle morphology. For a meaningful characterization of a powder sample, many particles have to be analyzed. Therefore, automated image analysis is performed using specific software for the calculation of various shape descriptors (Turchiuli et al., 2005).

Several articles on morphological characterization of powder products can be found in the literature, especially on chemical and pharmaceutical substances (Bika et al., 2005; Pons et al., 2002; Belaroui et al., 2002), foods (Jinapong et al., 2008; Faria et al., 2003), and model-products (Turchiuli et al., 2005).

Souza \& Menegalli (2011) and Dacanal et al. (1999) have conducted studies in which they obtained the morphological characterization of particles using the size and shape descriptors by image analysis. In a research conducted by Souza, the product studied was guava juice powder, and the focus was to determine 
the minimum number of particles to be evaluated focusing on calculating the size distribution and shape of the granules obtained in fluidized bed. The Chi-Square test proved to be a robust and efficient method to determine the particle size distribution and particle shape characterization; 550 particles were found to be the minimal number of particles necessary for the determination of the particle size distributions, and 100 particles were required for determination of the shape descriptors for the specific material studied. Dacanal studied the changes in the morphological properties of soy protein isolate during the agglomeration process in a pulsed fluidized bed. The results obtained by this author demonstrated that the shape of the raw powder particles were circular and compact, while the agglomerated particles were wrinkled and had low circularity and tight solid bridges.

The bi-dimensional analysis, combining microscopy and software, have made possible to characterize the granule shape thus obtaining qualitative and quantitative information about its morphology. Image analysis is performed using specific software to determine the shape descriptors, and it requires several descriptors in order to characterize the shape of the cocoa beverage powder granules. In addition, descriptors should be invariant with respect to particle size and position in the image.

Simple shape descriptors are obtained from size measurements of the perimeter of the particle. The equivalent diameter $\left(\mathrm{D}_{\text {eq }}\right)$ of the particle, for example, can be determinate by the projected area (S) of the silhouette of the particle (Turchiuli et al., 2005) (Equation 1).

$D_{e q}=2(S / \pi)^{1 / 2}$

Another common shape descriptor used is the particle circularity $\mathrm{C}$, which is determined by the association of the silhouette perimeter $\mathrm{P}$ with the projected area $\mathrm{S}$ (Equation 2).

$C=4 \pi S / P^{2}$

The circularity $(\mathrm{C})$ compares the surface of the object to that of the circle of same perimeter $(\mathrm{P})$. The circularity is equal to 1 for the circle and increases when the particle becomes different from this form of reference, characterizing the particle elongation or irregularity of the surface (Pons et al., 2002). If C is less than 1.25 , the particle is called circular, if $\mathrm{C}$ is between 1.25 and 2 , the particle is angular, and if $\mathrm{C}$ is greater than 2 , the particle is elongated (Turchiuli et al., 2005). The more irregular or the more elongated particle, the larger the value of $\mathrm{C}$. The maximal and minimal Feret diameters are generally associated to the length and width of the particle, and they are used to determinate its elongation. If the elongation is equal to 1 , the object is circular or square; for values greater than 1 , the object becomes elongated (Turchiuli et al., 2005) (Equation 3).

$$
\Psi=F_{\max } / F_{\min }
$$

The Compacity $(\mathrm{Co})$ is obtained by the ratio of $\mathrm{D}_{\text {eq }}$ to $\mathrm{F}_{\max }$ ' characterizing the elongation of the particle, and the more elongated the particle, the lower the value of Co (Equation 4).

$C o=D_{e q} / F_{\max }$
Based on the relationship between the real perimeter of the object $(\mathrm{P})$, and the perimeter of its external convex polygon $(\mathrm{Pc})$, it is possible to determine the roughness or convexity $(\mathrm{Rc})$ of the particle. According to Pons et al. (1999) the roughness can be calculated as (Equation 5):

$R_{c}=P / P_{c}$

An important factor to be considered in order to obtain reliable size and shape descriptors, using image analysis, is the minimum number of particles to be analyzed (Souza \& Menegalli, 2011; Linoya et al., 1991; Allen, 1997). There is no consensus on the minimum number of particles to be evaluated, Pons et al. (1999) evaluated 100 particles; Turchiuli et al. (2005) evaluated 150 particles, and Faria et al. (2003) and Dacanal (2009) evaluated 500 particles. According to Souza \& Menegalli (2011), the minimum number of particles is considered to be the number in which the stabilization of the mean value and the standard deviation of all descriptors occur. Other authors have simply set the number of particles to be analyzed without considering the variation in standard deviations. Some examples are Wang (2006), who analyzed 2000 particles for the determination of the accumulated particle size distribution, and Shah et al. (2006), who analyzed 200 particles to evaluate the average diameter.

In order to obtain a sufficient number of the particles analyzed, not more than necessary, which implies unnecessary work, focusing on simplifying the analysis and avoiding inaccuracy of the average values of the parameters measured, in this study, the variation of the parameter measured and the standard deviation of the readings were plotted as a function of the number of particles analyzed until the parameter measured and the standard deviation were stabilized. The same procedure was used to evaluate size and shape descriptors in different studies (Turchiuli et al., 2005; Faria et al., 2003; Pons et al., 1999; Souza, 2007).

The objective of this study was to characterize the morphology of cocoa beverage powder granules obtained using different operating conditions of a steam agglomerator (minimal, average and maximal), by image analysis of the size and shape descriptors.

\section{Materials and methods}

\subsection{Materials}

The cocoa beverage powder used in this study were obtained by steam agglomeration and had the following composition: $80 \%$ sugar (Copersucar supplier, specification type 3 crystal, subjected to pre-treatments to get the granulated sugar); $12 \%$ corn maltodextrin (Corn Products supplier, specification type 20 D.E.); $8 \%$ cocoa powder (Barry Callebaut, a Brazilian supplier, specification type: RL/alkaline, 11-12\% cocoa butter). It was applied $0.3 \%$ of natural, low viscosity soybean lecithin (specification type: Solec $\mathrm{L}, \mathrm{T}=25^{\circ} \mathrm{C}-\mu=2900 \mathrm{cP}$, provided by Solae Company, a Brazilian supplier) based on the weight of the formulation. 


\subsection{Cocoa beverage powder}

The cocoa beverage powder was formulated using granulated sugar. The pre-treatments used to obtain the granulated sugar were: grounding twice using a knives/hammers mill (Treu; screnn $3.2 \mathrm{~mm}$ opening diameter; Brazil) and sieving through a $1.19 \mathrm{~mm}$ sieve mesh. The components of the cocoa beverage powder were then mixed using a ribbon mixer (Inco; Brazil), with capacity for $20 \mathrm{~L}$ of powder, under the following process conditions: $25^{\circ} \mathrm{C}, 120 \mathrm{rpm}$, and $20 \mathrm{~min}$.

Lecithination was carried out using the same equipment under the same conditions that were used to mix the ingredients. The content of the lecithin sprayed was $0.3 \%$, as indicated by Vissotto et al. (2006) for cocoa beverage powders that would further be agglomerated using steam.

A steam agglomerator was used in the present study (ICF Industrie Cibecs. p.a.; Italy; type: mini-instant pilot). The material was fed into the agglomerator by means of a vibrating dosing chute (MVL Máquinas vibratórias Ltda, Brazil; type: FTO); the powder flow was directed towards the center of the feed hopper, on the inside of which there was a rotary brush that forced the passage of the powder against a perforated screen $\left(6,25 \mathrm{~mm}^{2} \mathrm{mesh}\right)$. As the cocoa beverage powder descended, it was moistened by the steam coming from the diffuser. The granules formed were fed into the rotary dryer and were collected after the drying stage.

Granules of cocoa beverage powders were obtained at three different process conditions that represent the lower values (minimal), average condition (medium), and the process condition used at the highest values (maximal), which were chosen among the several process conditions studied by Vissotto et al. (2010). The conditions used in steam agglomeration process are presented in Table 1. The processing experimental tests were performed in triplicate.

\subsection{Morphological and image analyses}

\section{Size and shape descriptors}

Samples were characterized by determination of the size and shape descriptors: area, Feret diameters, aspect ratio, roughness, perimeter of the particle and convex bounding polygon, compacity, and circularity. Each sample of agglomerated cocoa beverage powder and the raw materials were separated according to their size in sieves $(1190,850,600,425,300,212,150 \mu \mathrm{m}$ mesh and sieve bottom) using a mechanical agitator (Produtest, Brazil) and rheostat intensity 6 for 5 minutes, conditions that

Table 1. Steam agglomeration process conditions.

\begin{tabular}{lccc}
\hline \multirow{2}{*}{ Variables } & \multicolumn{3}{c}{ Process conditions } \\
\cline { 2 - 4 } & Cond $_{\max }$ & Cond $_{\text {med }}$ & Cond $_{\min }$ \\
\hline Steam pressure $-\mathrm{P}_{\mathrm{v}}($ bar $)$ & 1.8 & 1.4 & 1.0 \\
Air temperature of rotary dryer $-\mathrm{T}_{\mathrm{a}}\left({ }^{\circ} \mathrm{C}\right)$ & 100 & 95 & 90 \\
Dryer rotation $-\mathrm{R}_{\mathrm{d}}(\mathrm{rpm})$ & 52 & 32 & 12 \\
Solids feed rate $-\mathrm{V}_{\mathrm{s}}(\mathrm{g} / \mathrm{min})$ & 700 & 550 & 400 \\
\hline
\end{tabular}

Constant drying air speed $=1.45 \mathrm{~m} / \mathrm{s}$. led to less extensive granule breakage. The particles retained on each sieve were collected in Petri dishes and analyzed in the microscope to capture the images. This separation was carried out to allow a better image of the particles because it was not possible to visualize particles with different sizes in the same image. The particles distributed into 8 Petri dishes for each sieve after the capture of images were photographed; the particles were discarded to ensure that they were not repeatedly photographed. For the morphological analysis a SZX9 stereoscopic microscope coupled to a Sony CCD-IRIS camera was used. The images were analyzed using the software Image-Pro ${ }^{\circledR}$ Plus - version 4.2 for Windows TM from Media Cybernetics.

\section{Results and discussion}

\subsection{Size and shape descriptors}

The size and shape descriptors were determined for at least 150 particles, ensuring the stabilization of the standard deviation and the average value for each descriptor. The samples analyzed were obtained from the product mixture under the three process conditions studied (Cond ${ }_{\min }$, Cond $_{\text {med }}$, Cond ${ }_{\text {max }}$ ), and the determinations were made in triplicate.

Figure 1 and 2 show the effect of the number of particles on the average value and standard deviation for the size descriptors and for the shape descriptors.

According to a study conducted by Turchiuli et al. (2005), 150 was the minimum reliable number of particles measured to determine the descriptors in order to characterize the granules obtained by fluidized bed agglomeration. Souza \& Menegalli (2011) verified that the minimum number of particles to be used depends of the material, shape, and the operator and must be determined for each material.

The size and shape descriptors were determined for 150 particles for each of the sieve opening size (Figures 3 and 4). Size descriptors as a function of sieve opening size are shown in Figure 3.

It can be seen that under the three process conditions studied (Table 1), the granules differ in size descriptors (area, perimeter, Feret diameters) at the sieves opening larger than $600 \mu \mathrm{m}$ (Figure 3 ). Thus, the process conditions really influence the morphology of the larger particles obtained by granulation. It was also noted that under minimal process condition Cond ${ }_{\text {min }}$, particles with higher area, perimeter, and minimal and maximal Feret diameters were obtained. Another fact is that the solid feed rate has some influence on the size of the granule formed because the smaller the flow of the powder in the feed hopper of the agglomerator, the bigger the granules obtained, for a constant amount of steam due to a higher ratio of solid flow to agglomerating agent.

Shape descriptors as a function of sieve opening size are shown in Figure 4.

The aspect ratio of the particle $(\Psi)$ obtained from the relationship between the maximal and minimal Feret diameters allows to evaluate how much the particle is elongated. The more the value of the aspect ratio differs from 1, the more elongated 
(a)

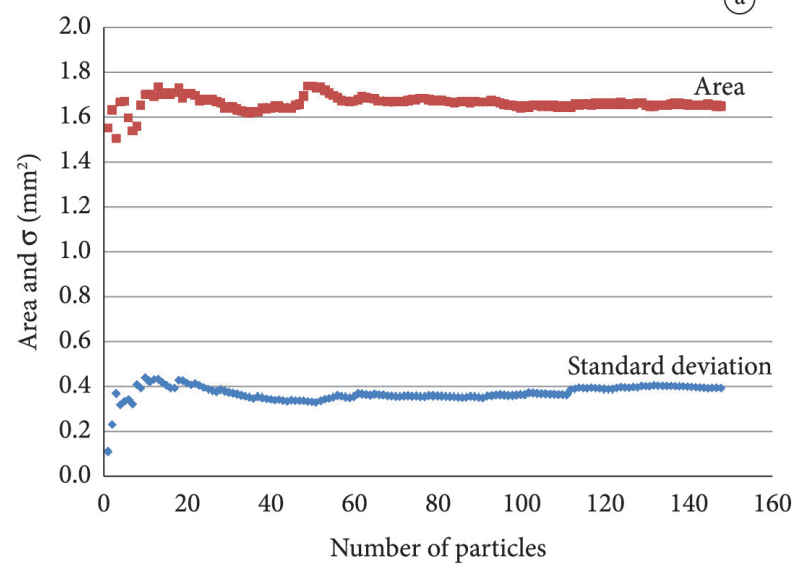

(c)

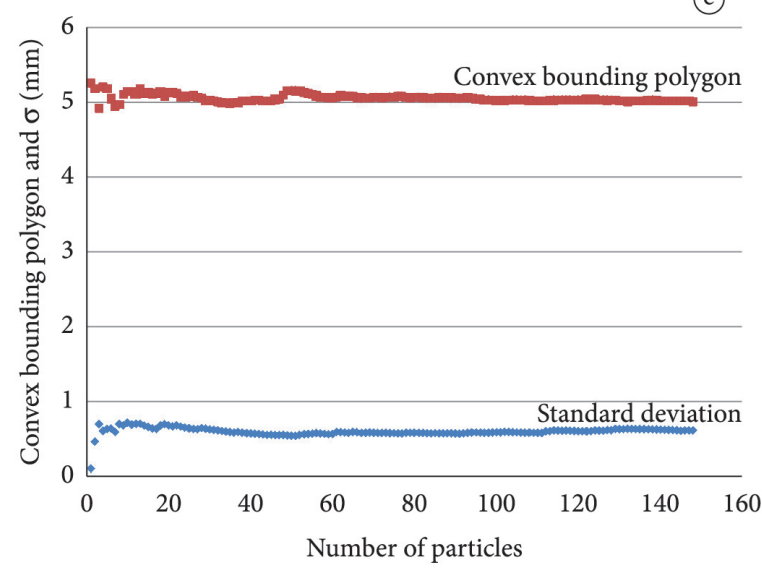

(b)

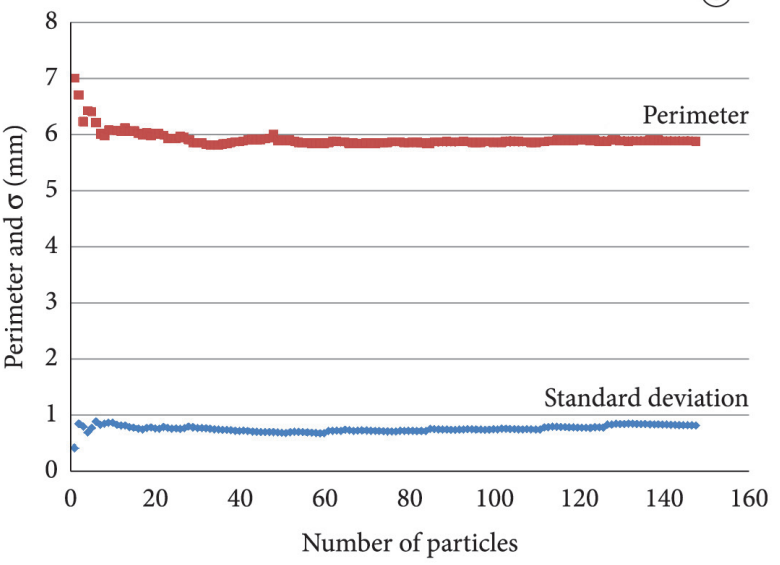

(d)

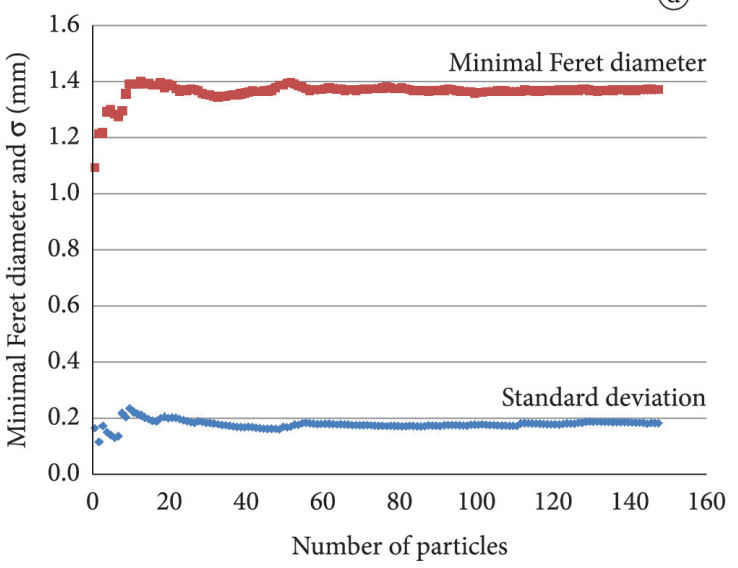

(e)

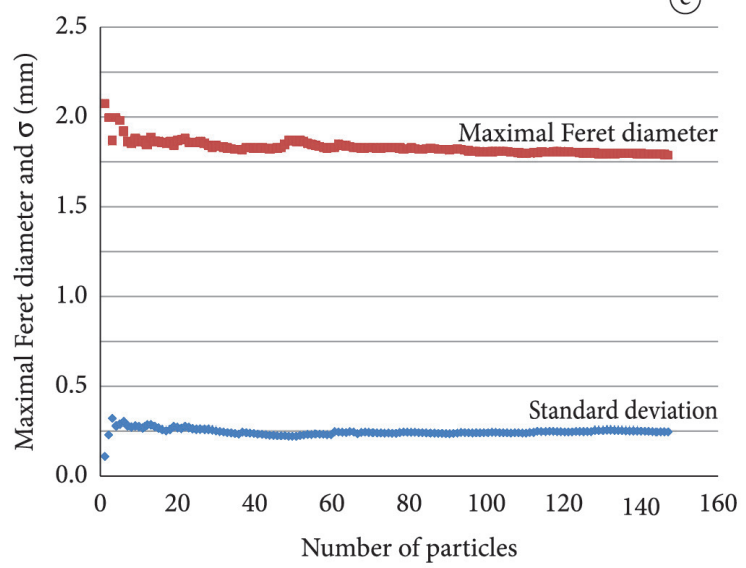

Figure 1. Effect of the number of particles on the size descriptors and the standard deviations $(\sigma)$ of the particle measurements of the steamagglomerated cocoa beverage powder. Size descriptors: area (a), perimeter (b), convex bounding polygon (c) and minimal (d) and maximal (e) Feret diameters.

the particle. The different process conditions evaluated for the steam agglomeration allowed the formation of elongated granules, as shown in Figure 4. The particles larger than $600 \mu \mathrm{m}$ had a more spherical shape than that of the smaller particles.

The granules of cocoa beverage powder had similar roughness (convexity) values at the three process conditions studied, as shown in Figure 4. The particles distributed in the sieve opening $0 \mu \mathrm{m}$-sieve bottom are less rough than the other granules since they are a fine powder. As the size of the particles increases from 0 to $212 \mu \mathrm{m}$, there was an increase in roughness, but in the particles of size between 212 and $1190 \mu \mathrm{m}$, it tended to decrease.

According to the classification of Turchiuli et al. (2005), the granules obtained by steam agglomeration are elongated 
(a)

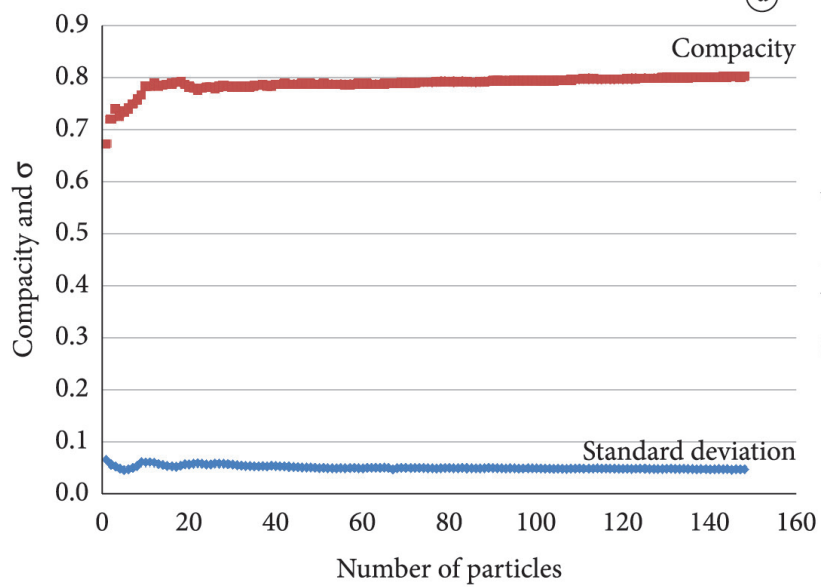

(c)

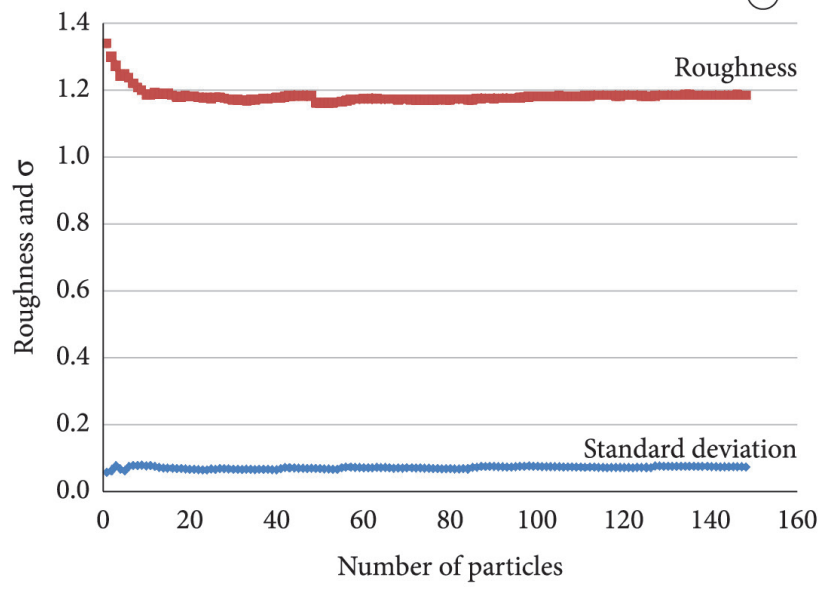

(b)

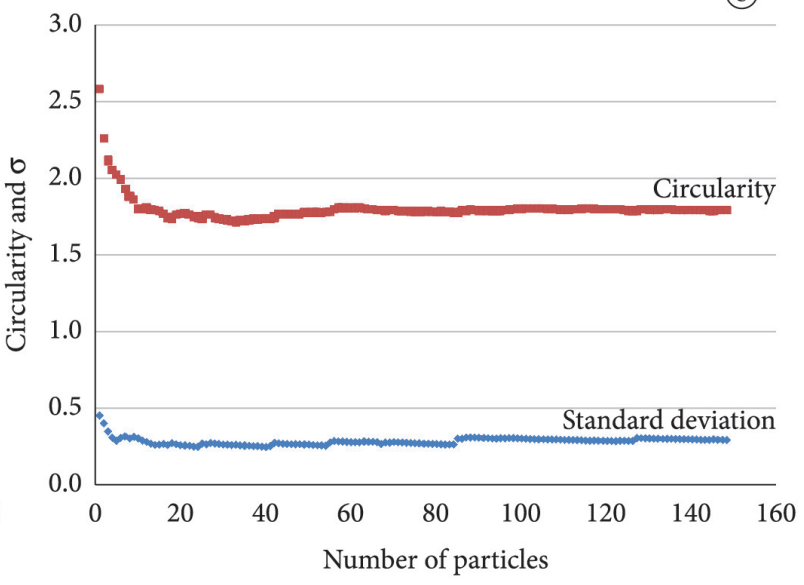

(d)

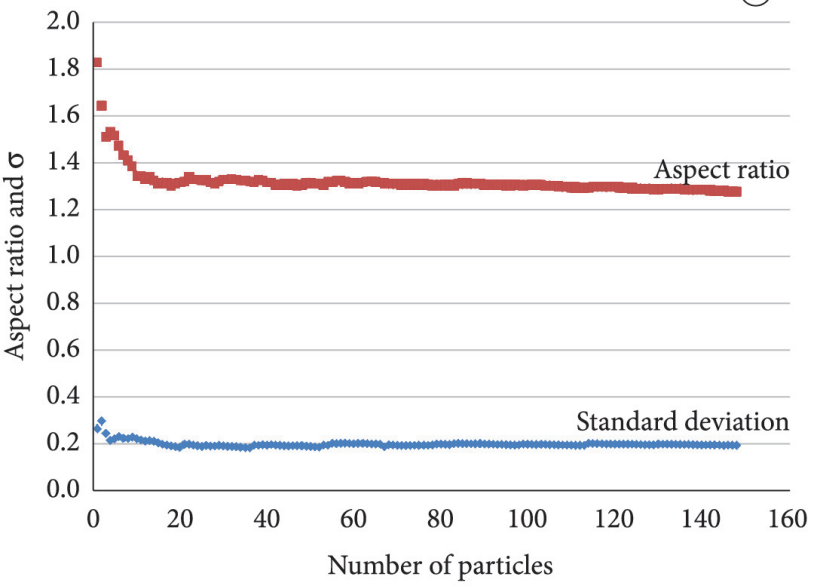

Figure 2. Effect of the number of particles on the shape descriptors and the standard deviations $(\sigma)$ of the particle measurements of the steamagglomerated cocoa beverage powder. Shape descriptors: compacity (a), circularity (b), roughness (c) and aspect ratio (d).

particles. Only the granules of larger diameter, distributed in the sieve opening size between 850 and $1190 \mu \mathrm{m}$, are angular particles $(1.25<\mathrm{C}<2)$. At the different process conditions evaluated, there is a similar trend for the circularity of the particles, as shown in Figure 4.

The compacity of the particles showed no variation at the different process conditions studied (Figure 4). Particles smaller than $425 \mu \mathrm{m}$ were less round, and, therefore, they were longer, which can be confirmed by the higher circularity values $(C>2.0)$ in Figure 4. For the particles greater than $425 \mu \mathrm{m}$, there is an increase in compacity, and consequently, the particles tend to approach spherical shapes.

\subsection{Particle size distribution and influence of process conditions}

Figure 5 shows the particle size distributions for the cocoa beverage powder agglomerated under the process conditions Cond $_{\text {min }}$, Cond ${ }_{\text {med' }}$, and Cond ${ }_{\text {max }}$, respectively.

For the process conditions Cond ${ }_{\min }\left(\mathrm{P}_{\mathrm{v}}=1.0\right.$ bar; $\mathrm{T}_{\text {secrot }}=90^{\circ} \mathrm{C} ; \mathrm{V}_{\text {solalim }}=400 \mathrm{~g} / \mathrm{min} ; \mathrm{R}_{\text {sec }}=12 \mathrm{rpm}$ ) and Cond ${ }_{\max }$ $\left(\mathrm{P}_{\mathrm{v}}=1.8\right.$ bar; $\left.\mathrm{T}_{\text {secrot }}=100^{\circ} \mathrm{C} ; \mathrm{V}_{\text {solalim }}=700 \mathrm{~g} / \mathrm{min} ; \mathrm{R}_{\text {sec }}=52 \mathrm{rpm}\right)$, a heterogeneous distribution of particle size was observed, with a large concentration of granules retained on the sieves of sizes between 300 and $850 \mu \mathrm{m}$. In these process conditions, it was observed a small formation of granules with size equal or greater than $1190 \mu \mathrm{m}$. The cocoa beverage powder obtained at the process condition Cond ${ }_{\text {med }}\left(\mathrm{P}_{\mathrm{v}}=1.4 \mathrm{bar} ; \mathrm{T}_{\text {sec rot }}=95^{\circ} \mathrm{C}\right.$; $\mathrm{V}_{\text {solalim }}=550 \mathrm{~g} / \mathrm{min} ; \mathrm{R}_{\text {sec }}=32 \mathrm{rpm}$ ) showed a homogeneous distribution of particle size, especially for particle sizes between 300 and $850 \mu \mathrm{m}$.

At the Cond ${ }_{\max }$ condition, there were $75.5 \%$ of particles retained in the sieves of opening sizes between 300 and $1190 \mu \mathrm{m}$; at the process Cond ${ }_{\text {med }}$ condition, it was observed that $80.6 \%$ of the granules were retained in the same range of opening sieves, and at the Cond ${ }_{\min }, 81.1 \%$ of the product granules were retained. Analysis of variance (Tukey's test for $\mathrm{p} \leq 0,05$ ) was performed, and the results showed that the amount of particles retained on the sieves with opening sizes between 1190 and $300 \mu \mathrm{m}$ differed for the 3 conditions studied (Cond ${ }_{\max }=75.5 \pm 0.1^{c}$; Cond $_{\text {med }}=80.6 \pm 0.1^{\mathrm{b}} ;$ Cond $\left._{\min }=81.1 \pm 0.1^{\mathrm{a}}\right)$. Therefore, it appears that a higher percentage of larger granules (retained on the sieves with opening sizes between 300 and $1190 \mu \mathrm{m}$ ) were obtained under the agglomeration Cond ${ }_{\min }$ condition. 
(a)
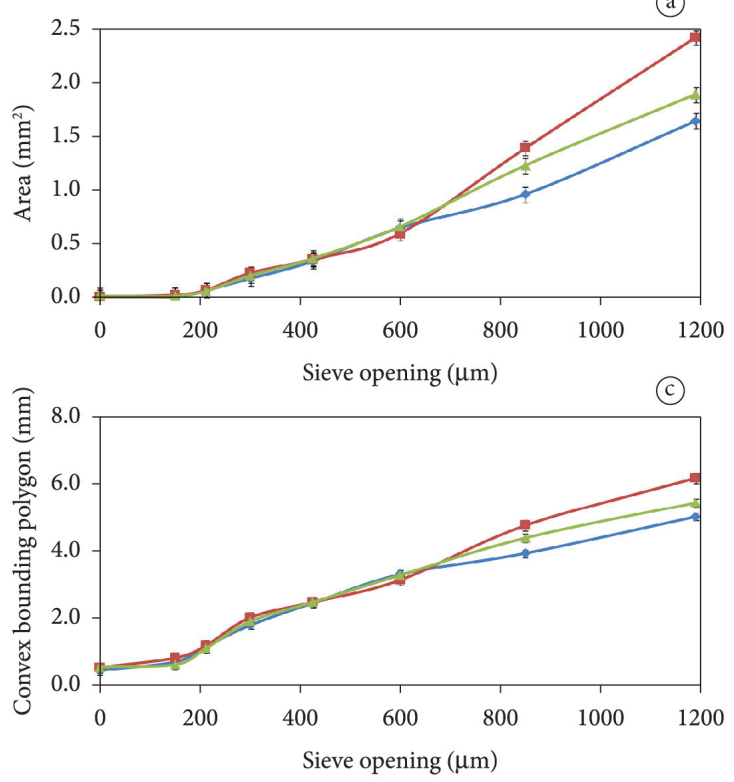

(b)

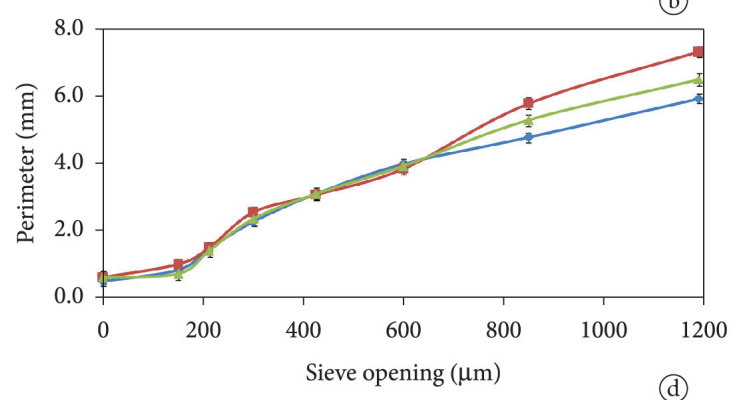

(d)

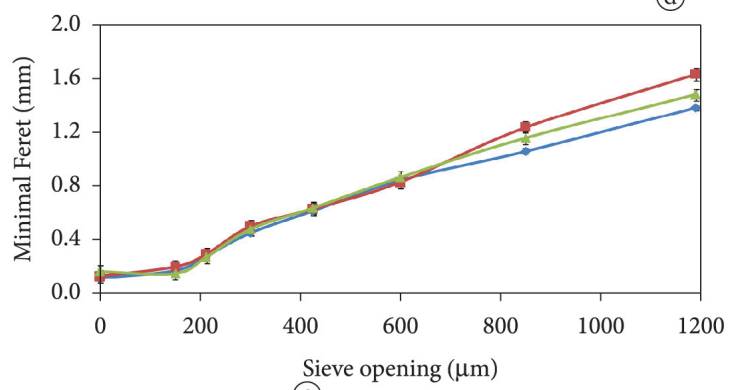

(e)

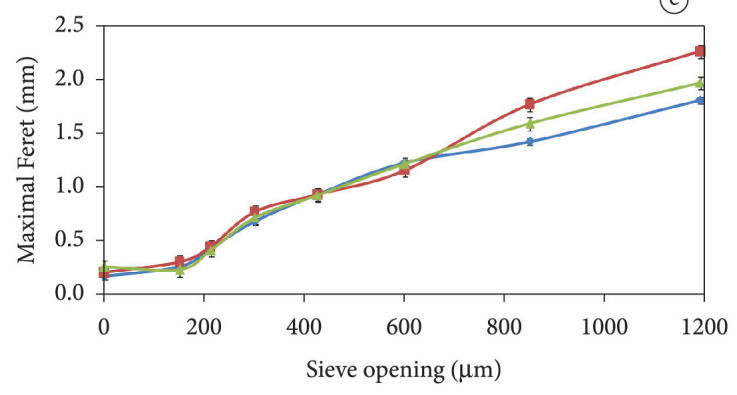

$\rightarrow-$ Condmax $\rightarrow-$ Condmin $\rightarrow-$ Condmed

Figure 3. Size descriptors as a function of the granulometric distribution of the steam-agglomerated cocoa beverage powder evaluated under the process conditions $\left(\right.$ Cond $_{\text {max }}$, Cond ${ }_{\text {med }}$, Cond ${ }_{\text {min }}$ ). Size descriptors: area (a), perimeter (b), convex bounding polygon (c), minimal Feret diameter (d), and maximal Feret diameter (e).
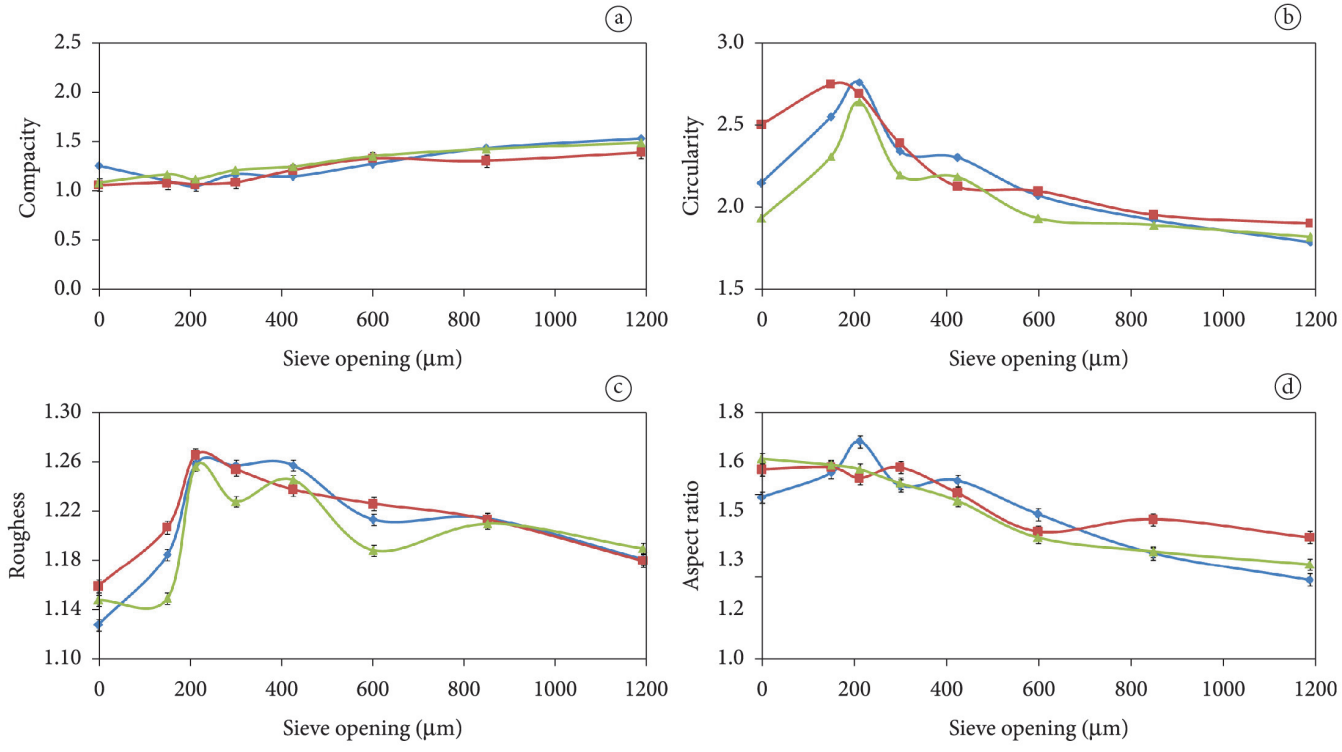

$\leftrightarrow \rightarrow$ Condmax $\rightarrow-$ Condmin $\rightarrow$ Condmed

Figure 4. Shape descriptors as a function of the granulometric distribution of the agglomerated cocoa beverage powder evaluated under the process conditions $\left(\mathrm{Cond}_{\text {max }^{\prime}}\right.$ Cond $_{\text {med }}$, Cond ${ }_{\text {min }}$ ). Shape descriptors: compacity (a), circularity (b), roughness (c), and aspect ratio (d). 
This confirms what was observed in Figure 3: under this condition, the ratio between the flow rate of the feed solids and vapor pressure was equal to 400:1.0 (g/min:bar). The low amount of solid feed $(400 \mathrm{~g} / \mathrm{min})$ for vapor pressure of $1.0 \mathrm{bar}$ led
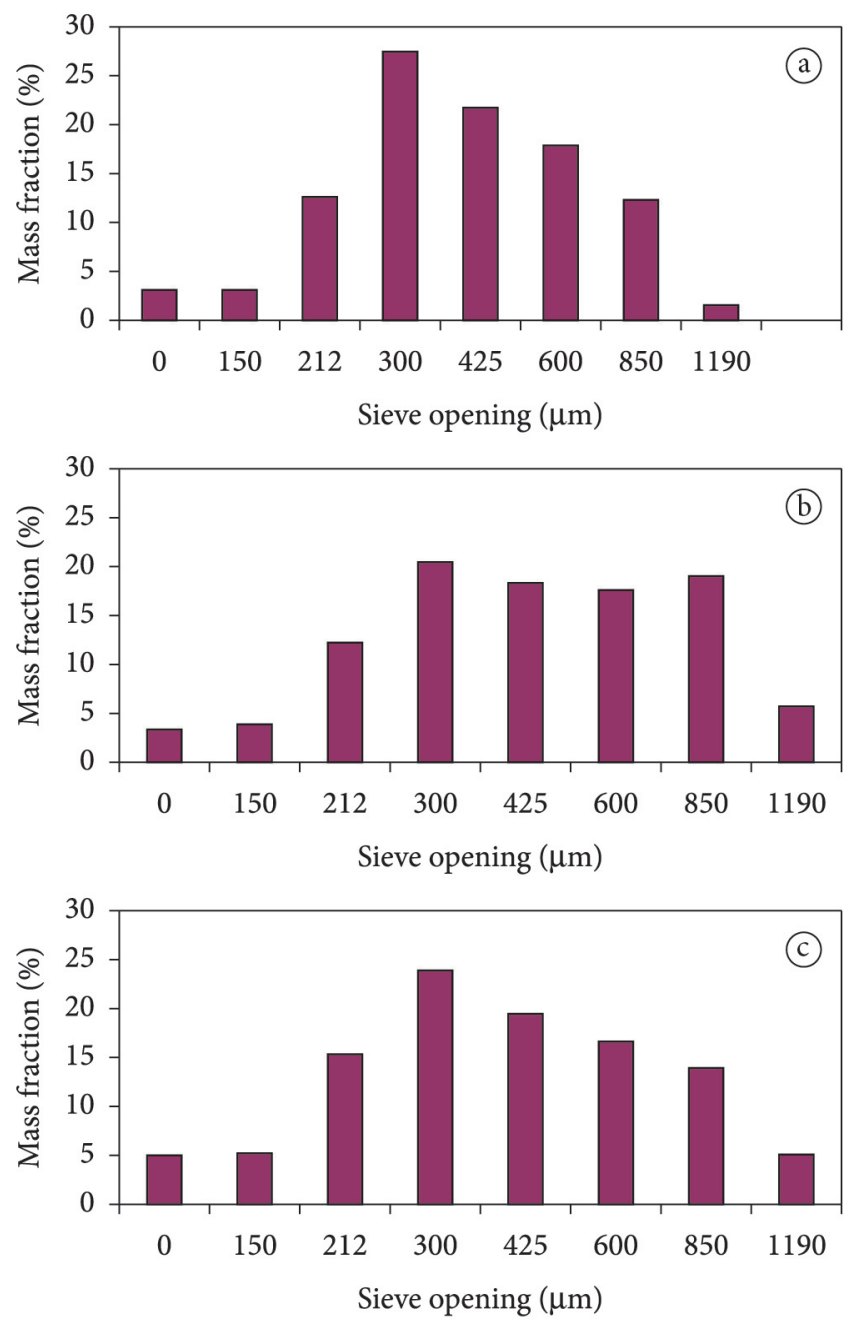

Figure 5. Particle size distribution of the cocoa beverage powder granules at the process conditions: Cond ${ }_{\min }$ (a), Cond ${ }_{\text {med }}$ (b), and Cond $_{\text {max }}(c)$. to an optimal granulation condition, thus resulting in a greater amount of larger granules.

At the Cond ${ }_{\text {max }}$ condition, the relationship between solid flow and vapor pressure was equal to 700:1.8 (g/min:bar), and although there was a relatively high amount of steam (1.8bar), the amount of solid feed was high $(700 \mathrm{~g} / \mathrm{min})$. The relationship between solid flow and vapor pressure in this case was lower than that obtained at the Cond ${ }_{\text {min }}$ condition (Cond $_{\text {min }}=400: 1$; Cond $\left._{\text {max }}=388.89: 1\right)$. At this process condition, therefore, there was an amount of solids in the feed below the optimum granulation, explaining only $75.5 \%$ of the particles retained on sieves of greater diameter, i.e., large particles. On the other hand, at the Cond ${ }_{\text {med }}$ condition, the relationship between the solid flow and vapor pressure was 550:1.4 (g/min:bar) and therefore, equal to $392.86: 1$.This explained the amount of $80.6 \%$ of the largest diameter granules retained, which would be an intermediate value for the retention of particles between the values of the conditions Cond $_{\text {min }}(81.1 \%)$ and Cond $_{\text {max }}$ (75.5).

The drying temperature and rotation of the rotary dryer, at the process condition Cond ${ }_{\text {max }}$ was $100^{\circ} \mathrm{C}$ and $52 \mathrm{rpm}$, and at the condition Cond $\mathrm{min}_{\text {min }}$ it was $90^{\circ} \mathrm{C}$ and $12 \mathrm{rpm}$. An excessive drying of the granules at $100^{\circ} \mathrm{C}$ explains the formation of more brittle particles which, when subjected to the high rotation (52rpm Cond $_{\text {max }}$ ), are broken in the rotary dryer, and therefore, there was a formation of a greater percentage of particles of smaller diameter $(10 \%$ of the particles retained on sieves of $150 \mu \mathrm{m}$ and the sieve bottom). At the minimum condition $\left(\mathrm{Cond}_{\min }\right)$, the amount of small particles retained on these same sieves was $6 \%$, which is much smaller than that obtained for the Cond ${ }_{\text {max }}$ condition since the drying temperature was below $90{ }^{\circ} \mathrm{C}$ and the rotation of the dryer (12rpm) was also lower, which led to less extensive granule breakage.

\subsection{Comparison of the cocoa beverage powder granules under the process conditions}

Figure 6 shows a comparison between the cocoa beverage powder granules obtained under different conditions of steam agglomeration: Cond ${ }_{\text {max }}$ Cond med $_{\text {, }}$ and Cond ${ }_{\text {min }}$. It was observed that the granules differ in size and that the higher particles were formed under the Cond ${ }_{\text {min }}$ process condition.
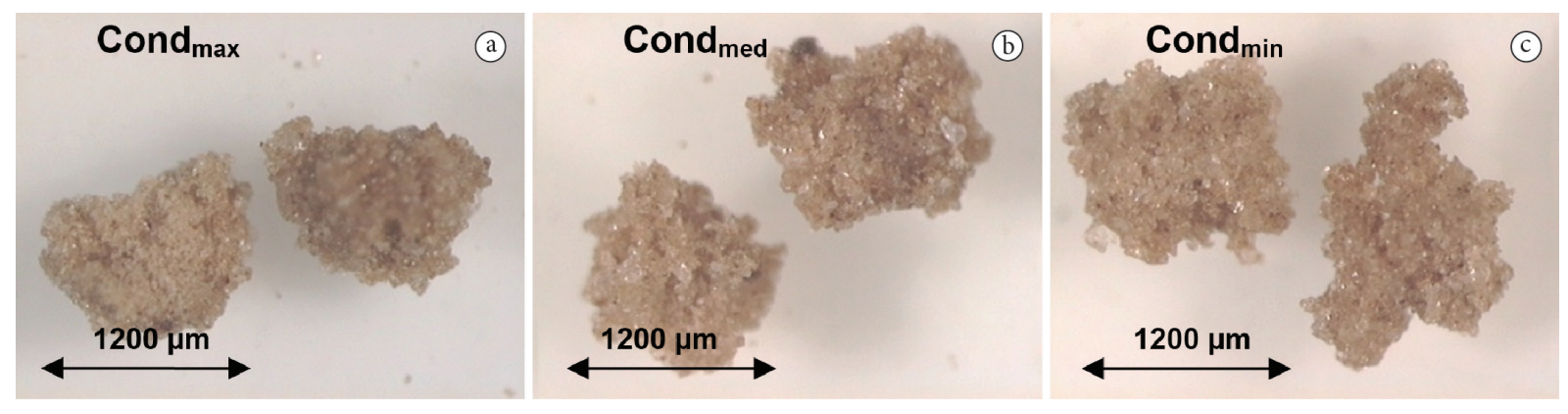

Figure 6. Comparison of the cocoa beverage powder granules under the process conditions: (a) Cond max , (b) Cond med and (c) Cond ${ }_{\text {min }}$ for $\mathrm{Dp} \geq 1190 \mu \mathrm{m}$. 


\section{Conclusions}

The method used in this study allowed characterizing the granules of cocoa beverage powder obtained by steam agglomeration using size and shape descriptors. The minimal number of particles evaluated (150) allowed obtaining more accurate values for the size and shape descriptors of the granules. It was concluded that the granules of cocoa beverage powder agglomerated by steam have elongated shape. There were no differences between the process conditions studied (minimal, average, and maximal) when they were compared using the particle shape descriptors (aspect ratio, compacity, circularity, and roughness). As for the size descriptors (area, perimeter, Feret diameters, and convex bounding polygon), there was a difference between the process conditions for particles with size greater than $600 \mu \mathrm{m}$. With regard to the minimal process conditions, especially low solid feed rate, there was an increase in the values of size descriptors. In addition, at the minimum conditions of the process, in which the low amount of solid feed $(400 \mathrm{~g} / \mathrm{min})$ for steam pressure of $1.0 \mathrm{bar}$, it was obtained good granular condition with retention of $81.1 \%$ of granules on sieves with aperture size between 300 and $1190 \mu \mathrm{m}$.

\section{References}

Allen, T. (1997). Particle size measurement (2a. ed., 525 p.). London: Chapman \& Hall.

Belaroui, K., Pons, M. N., \& Vivier, H. (2002). Morphological characterization of gibbsite and alumina. Powder Technology, 127(3), 246-256. http://dx.doi.org/10.1016/S0032-5910(02)00112-2.

Bika, D., Tardos, G. I., Panmai, S., Farber, L., \& Michaels, J. (2005). Strength and morphology of solid bridges in dry granules of pharmaceutical powders. Powder Technology, 150(2), 104-116. http://dx.doi.org/10.1016/j.powtec.2004.11.024.

Dacanal, G. C. (2009). Aglomeração de polpa de acerola e proteína isolada de soja em pó em leito fluidizado cônico e pulsado (Tese de Doutorado). Faculdade de Engenharia de Alimentos, Universidade Estadual de Campinas, Campinas.

Dacanal, G. C., Hirata, T. A. M., \& Menegalli, F. C. (1999). Fluid dynamics and morphological characterization of soy protein isolate particles obtained by agglomeration in pulsed-fluid bed. Powder Technology, 103, 44-57.

Faria, N., Pons, M. N., Feyo de Azevedo, S., Rocha, F. A., \& Vivier, H. (2003). Quantification of the morphology of sucrose crystals by image analysis. Powder Technology, 133(1-3), 54-67. http://dx.doi. org/10.1016/S0032-5910(03)00078-0.

Hla, P. K., \& Hogekamp, S. (1999). Wetting behavior of instantized cocoa beverage powders. International Journal of Food Science \& Technology, 34(4), 335-342. http://dx.doi.org/10.1046/j.13652621.1999.00275.x.

Hogekamp, S. (1999a). Steam jet agglomeration - Part 1: Production of redispersible agglomerates by steam jet agglomeration. Chemical Engineering \& Technology, 22(5), 421-424. http://dx.doi.org/10.1002/ (SICI)1521-4125(199905)22:5<421::AID-CEAT421>3.0.CO;2-0.

Hogekamp, S. (1999b). Steam jet agglomeration - Part 2: Modeling agglomerate growth in a modified steam jet agglomerator. Chemical Engineering \& Technology, 22(6), 485-490. http://dx.doi.org/10.1002/ (SICI)1521-4125(199906)22:6<485::AID-CEAT485>3.0.CO;2-U.

Hogekamp, S., Schubert, H., \& Wolf, S. (1996). Steam jet agglomeration of water soluble material. Powder Technology, 86(1), 49-57. http:// dx.doi.org/10.1016/0032-5910(95)03037-9.
Iveson, S. M., Litster, J. D., Hapggod, K., \& Ennis, B. J. (2001). Nucleation, growth and breakage phenomena in agitated wet granulation processes: a review. Powder Technology, 117(1-2), 3-39. http://dx.doi.org/10.1016/S0032-5910(01)00313-8.

Jinapong, N., Suphantharika, M., \& Jamnong, P. (2008). Production of instant soymilk powders by ultrafiltration, spray drying and fluized bed agglomeration. Journal of Food Engineering, 84(2), 194-205. http://dx.doi.org/10.1016/j.jfoodeng.2007.04.032.

Knight, P. C. (2001). Structure agglomerated products for improved performance. Powder Technology, 119(1), 14-25. http://dx.doi. org/10.1016/S0032-5910(01)00400-4.

Kowalska, J., \& Lenart, A. (2005). The influence of ingredients distribution on properties of agglomerated cocoa products. Journal of Food Engineering, 68(2), 155-161. http://dx.doi.org/10.1016/j. jfoodeng.2004.05.028.

Linoya, K., Gotoh, K., \& Higashitani, K. (1991). Powder technology handbook (794 p.). New York: Marcel Dekker.

Omobuwajo, T. O., Busari, O. T., \& Osemwegie, A. A. (2000). Thermal agglomeration of chocolate drink powder. Journal of Food Engineering, 46(2), 73-81. http://dx.doi.org/10.1016/S02608774(00)00067-4.

Palzer, S. (2005). The effect of glass transition on the desired and undesired agglomeration of amorphous food powders. Chemical Engineering Science, 60(14), 3959-3968. http://dx.doi.org/10.1016/j. ces.2005.02.015.

Pons, M. N., Vivier, H., Belaroui, K., Bernard-Michel, B., Cordier, F., Oulhana, D., \& Dodds, J. A. (1999). Particle morphology: from visualisation to measurement. Powder Technology, 103(1), 44-57. http://dx.doi.org/10.1016/S0032-5910(99)00023-6.

Pons, M. N., Vivier, H., Delcour, V., Authelin, J. R., \& Paillères-Hubert, L. (2002). Morphological analysis of pharmaceutical powders. Powder Technology, 128(2-3), 276-286. http://dx.doi.org/10.1016/ S0032-5910(02)00177-8.

Shah, M. H., Biradar, S. V., \& Paradkar, A. R. (2006). Spray dried glyceryl monooleate-magnesium trisilicate dry powder as cubic phase precursor. International Journal of Pharmaceutics, 323(1-2), 18-26. http://dx.doi.org/10.1016/j.ijpharm.2006.05.040. PMid:16846704

Souza, D. O. C. (2007). Granulação de alimentos: caracterização morfológica das partículas e modelagem matemática do processo (Dissertação de Mestrado). Faculdade de Engenharia de Alimentos, Universidade Estadual de Campinas, Campinas.

Souza, D. O. C., \& Menegalli, F. C. (2011). Image analysis: Statistical study of particle size distribution and shape characterization. Powder Technology, 214(1), 57-63. http://dx.doi.org/10.1016/j. powtec.2011.07.035.

Turchiuli, C., Eloualia, Z., El Mansouri, N., \& Dumoulin, E. (2005). Fluidised-bed agglomeration: agglomerates shape and end-use properties. Powder Technology, 157(1-3), 168-175. http://dx.doi. org/10.1016/j.powtec.2005.05.024.

Vissotto, F. Z., Jorge, L. C., Makita, G. T., Rodrigues, M. I., \& Menegalli, F. C. (2010). Influence of the process parameters and sugar granulometry on cocoa beverage powder steam agglomeration. Journal of Food Engineering, 97(3), 283-291. http://dx.doi. org/10.1016/j.jfoodeng.2009.10.013.

Vissotto, F. Z., Montenegro, F. M., Santos, J. M., \& Oliveira, S. J. R. (2006). Avaliação da influência dos processos de lecitinação e de aglomeração nas propriedades físicas de achocolatado em pó. Ciência e Tecnologia de Alimentos, 26(3), 666-671. http://dx.doi. org/10.1590/S0101-20612006000300028.

Wang, W. (2006). Image analysis of particles by modified Ferret method - best-fit rectangle. Powder Technology, 165(1), 1-10. http://dx.doi. org/10.1016/j.powtec.2006.03.017. 